\title{
Autumn Winter 2020 Design Development For Kids Girls (2-8 YRS)
}

\author{
Angel $\mathrm{M}^{1}$ and Nirmala Varghese ${ }^{2}$ \\ \{angelmarshalin.j@gmail.com ${ }^{1}$,rvn.afd@psgtech.ac.in ${ }^{2}$ \}
}

M.Sc. Fashion Design \& Merchandising, Department of Apparel and Fashion Design, PSG

College of Technology, Coimbatore, India ${ }^{1}$, Associate Professor with the Department of Apparel and Fashion Design, PSG College of Technology Coimbatore, India ${ }^{2}$

\begin{abstract}
Owing to the opening of several new businesses, the Indian retail industry has emerged as one of the strongest and fastest-growing industries. India is the world's fifthbiggest retail destination, based on research. Manufacturers are aiming their products at children who are more interested in the latest and upcoming fashion trends with decorated materials. Marketers have recently focused their attention on Indian children because the market for children's items has huge potential and is thriving. Exposure to global fashion trends, increased disposable income among India's working class, and the presence of foreign brands all contribute to the expansion of the kids clothing market. The expansion of the children's clothing sector has resulted in a huge increase in brand awareness among children. This provides a perfect opportunity for the organized players to lay a strong foundation in this segment. The project aims to develop a winter collection for 2-8YRS girls. The study provides a keen understanding on fashion trend analysis, developing of fashion boards and collection for kids wear market.
\end{abstract}

Keywords: Kids Wear, Fashion trend, Design Collection, Inter 2020, Retail.

\section{Introduction}

The Indian retail industry has become one of the most dynamic and fast-paced industries, thanks to the entry of various new firms. Total consumer spending is predicted to rise to about US $\$ 3,600$ billion by 2020 , up from US $\$ 1,824$ billion in 2017 . It contributes about $10 \%$ of the country's GDP and employs about $8 \%$ of the workforce. India is the fifth-largest shopping destination in the world. To create new jobs, the government is focusing on the manufacturing sector, and has launched a number of initiatives to that effect, including "Make in India." This will help to increase GDP per capita, putting more money in people's hands to improve their lifestyles and, as a result, promoting consumption and the retail business. In India, the market for children's clothes is expanding. To appeal to children who are more interested in new and future fashion trends, manufacturers employ pricey materials. Children's apparel is available in a wide range of styles and designs. Marketers have recently concentrated their efforts on Indian children because the market for children's products has enormous potential and is constantly growing.

The girls' apparel business was worth Rs 32,346 crore in 2017 , accounting for $48 \%$ of the whole kids wear sector. Exposure to global fashion trends, rising disposable money among 
India's working class, and the presence of foreign brands are all contributing to the growth of the kids clothing market . Children are becoming more conscious of brands as the kids apparel industry grows. This presents an excellent opportunity for organized players to get a firm footing in this industry. With 337 million children aged 0 to 14, India is the world's largest youthful population, accounting for $29 \%$ of the total population. In recent years, many multinational companies have entered India, encouraging the growth of children's clothes in the country.

\section{Literature Review}

\section{- $\quad$ Retail industry in India}

India's retail market is one of the fastest growing in the world as a result of its economic growth. From US\$ 672 billion in 2017, the Indian retail market is predicted to grow to US\$ 1,200 billion in $2021 \mathrm{~F}$. The e-commerce market in India is expected to grow at the fastest rate in the world [1].

The growing contribution of the services sector to India's overall GDP has improved working conditions and income for Indian households. India's GDP per capita reached \$2,000 for the first time in FY 2019. To create new jobs, the government is focusing on the manufacturing sector, and has launched a number of initiatives to that effect, including "Make in India." This will also help to increase GDP per capita, putting more money in people's hands to improve their lifestyles, boosting consumption and the retail industry.

\section{- $\quad$ Kids wear market in India}

The market for children's apparel is always expanding. Manufacturers are targeting children who are particularly interested in new and future fashion trends using beautiful materials. In India, unorganized and local businesses control a substantial portion of the children's clothing market. This provides organized players with a fantastic opportunity to establish a strong foothold in this market. In terms of children's clothes, the Indian market is gradually shifting toward an international focus. Cotton is used extensively in children's apparel. Cotton is worn by 86 percent of children. With national and international brands, India's market for branded children's clothes is growing. The children's apparel market accounts for almost $20 \%$ of the entire clothing market and is predicted to increase at a CAGR of 10.5 percent over the next ten years. At a present estimated value of Rs 45,220 crore ( $\$ 8,222$ million), the market is expected to reach Rs 123,030 crore ( $\$ 22,369$ million) by 2023. Disorganized players prevailed in the past, offering a wide range of styles at a low price and aiming for bigger quantities. Designer clothing, on the other hand, is gradually taking over as the preferred alternative for youngsters. Many domestic and foreign enterprises are expanding their portfolios and geographic regions to take advantage of India's burgeoning children's clothing market [3].

\section{- Behavior of Indian children}

There's no denying that children are a key marketing zone, and that they now hold a position in society that their parents never did. They aren't just customers; they play a direct or indirect role in their parents' purchase decisions. With the expansion of the tiny family system in which the child stays central, the nagging influence they have on their parents grows day by day. Children's influence varies depending on the type of goods, the decision stage, the family, the children, and the parents' demographics, among other factors. Children are no longer just 
passive observers; they now play an important role in households and have a considerable impact on their parents' purchasing decisions. The rising influence of children on parental purchasing decisions in most industrialized countries can be due to various factors [4]. The age of the children was thought to be a critical factor in determining the extent to which the children influenced their parents' purchasing decisions. According to McNeal and Yeh (2003), there is a link between age and effect on parents' purchasing decisions [5]. Youngsters that are older have more influence than children who are younger [6]. The influence of the child on the family's purchasing decision increases as the child's age increases. This is related to the child's cognitive capacities developing [7].

- Buying behavior

Children are an important target market category that also deserves a lot of attention from a marketing standpoint. Researchers have turned their attention to examining the influence of children because of the role they play in decision-making that affects the entire family. Depending on the product category and stage of the decision-making process, children have varying degrees of effect. They are active initiators, information searchers, and customers for some things, while they influence parental purchases for others. The way people are socialized to act as consumers' influences how they buy. Children's influence on a family's purchase decision must be investigated in a unique setting. In terms of family makeup and structure, values, conventions, and behaviour, Indian society differs greatly from Western society, all of which influence the role of children play in family purchasing decisions. Due to time restrictions and economic impacts in dual career families, children integrate well into the consumer role. Furthermore, exposure to the media and interactions with parents enable youngsters to not only be aware of new brands that are accessible, but also to understand how to evaluate them based on various criteria. Identifying the motives, interests and outlook of youngsters who demonstrate the most participation in buying a certain product aids in the formulation of marketing strategies. To help marketers grasp the chosen qualities of these customers and offer them the correct messages, products for which youngsters function as buying agents must be discovered. Merchants have been paying close attention to Indian children recently, as the market for children's products has huge potential and is continuously expanding.

- Indian parents perspective towards brand loyalty and safety

Humans' primary nature is to provide parental care to their children by ensuring their safety and protection. The clothing worn by youngsters while conducting activities should give a high level of safety. It has been claimed that using trims such as cords or drawstrings in the hoods of children's clothes causes significant mishaps. As a result, wealthy countries such as the United States have enacted severe laws to protect the safety of children's clothing. It is critical for India to investigate the safety features of children's clothing. One of the brand's primary objectives is to establish consumer confidence, which can be accomplished by ensuring the safety of children's clothing. As parents always value their children's safety over money, buyers' perceptions of children's clothing could change if they focused more on assuring their children's safety. One approach to keep the kids safe is to choose a safe product. This notion may drive Indian children's clothing companies to create outfits that are safe for children. This presents an ideal chance for Indian children's clothing businesses to join a new market that is comprised of informed parents who may become devoted consumers in order to ensure the safety of their children.

- Growing kids wear market in India

In India's garment sector, the segment of children's wear is experiencing rapid expansion. In 2017, India's children's apparel market was worth Rs 66,904 crore, accounting for $20 \%$ of 
the country's total clothing market. Children's clothing is predicted to reach Rs 145,445 crore by 2027 , with a CAGR of 8.1 percent. In the $0-14$ age range, India has the world's highest youth population, accounting for 29 percent $(337$ million) of the total population. Many multinational companies have entered India in recent years due to the potential for expansion, promoting the rise of children's clothes in India. Faced with rising competition, achievement requires a blend of great quality, outstanding design, and the correct price-performance ratio.

- Girls wear market

In 2017, the girls' apparel market was worth Rs 32,346 crore, accounting for 48 percent of the whole children's clothing market. Over the following decade, it is predicted to expand at an annual rate of $8 \%$, reaching Rs 70,120 crore in 2027. Ethnic apparel, jeans, T-shirts, skirts, shirts, winter clothes, bottom wear, and uniforms are the most popular items on the Indian girls' clothing market. Ethnic wear and uniforms are the main two categories in this area, accounting for about $53 \%$ of the girls' clothing market. The rural population of India accounts for about $60 \%$ of the entire population, indicating ethnic wear clothing's dominance in the girls' wear segment in rural India. T-shirts and jeans are predicted to raise at high compound annual growth rates of 13 percent and 12.35 percent, respectively, due to increased media exposure and brand recognition in Tier II and III Indian cities.

- India: A hotspot for global kids wear fashion

In the world of children's clothing, India has a strong brand presence in both international and domestic markets. Exposure to global fashion trends, combined with the rising disposable income of India's working class and the presence of current foreign brands, serves as a catalyst for the growth of the children's clothing sector. Private labels and fashion designers, in addition to Indian businesses, are exploring the Indian market for children's apparel. Many apparel companies have developed their own private labels, which are fairly priced and offer greater value for money in terms of quality and sustainability. In 2016, the garment industry's share of corporate retail in India was 22 percent, and this figure is likely to rise. Through the execution of the GST, there is projected to be a significant movement from the unorganized to the organized corporate sector. The move in the apparel business toward corporate retail makes the children's clothes sector more attractive for brands and retailers.

- $\quad$ The road ahead

Growing brand awareness among youngsters enhanced the profitability of the children's clothes sector. The most difficult task is to grasp the complexities of consumer behaviour, the benefits of value pricing, and the selling of children's clothing. Despite a move from unorganized to corporate retail establishments, most Indian parents choose to shop for their children's apparel in local businesses. International and national companies are finding it difficult to get out to these hyper-local retailers. The clothes retail sector places a premium on quality and providing good value for money. Understanding the needs of the children's clothing market requires a well-thought-out strategy.

\section{Methodology}

- $\quad$ To explore WGSN and trend forecasting books

The designing process is carried out by exploring WGSN forecast on kids' trend for Autumn/Winter 2020. The concepts that are given already are to be analyzed properly concentrating on color, style, concept, print, accessories. The concept of kid's trend for this Autumn/Winter 2020/2021 will be "Tech-tility". Tech-tility tells the gap between the real and 
unreal. The theme talks about the fantasies or alien concepts more like avatars which is a virtual concept. The look depicts about the water or liquid like translucent material combined with more of futuristic materials. The data gives the concept of bio wear which reminds of abstract designs or tie $\mathrm{n}$ dye techniques and camouflage prints to trend which is to be more colorful. The concept of gaming squad, as the children spend more of their time with playing games. This concept gives the opportunities on inspiring game collection. The concept talks about the space nomad so from the name itself it can be guessed this is the theme about space with odd combination and killer color trends. This theme also specifies on pleats, crinkle folds and more of metallic textures. The concept of nature which is inspired by animal birds and butterflies. Sequins worked fabrics, the metallic and lurex concepts gives the appearance of forest dwelling for party wear garments. The concept of Y2K (YEAR 2OOO) tourist, it goes with vibrant colors mini backpack with playful looks and theme park concept by giving comfort high level zone to create kid-friendly look. The concept also talks about the bold designs with sequin embellishments. More like rainbow colors and all-over embellished styles for this opulence concept. The theme defines the puffed effect along with metallic and shimmery concepts goes with quilting in new silhouettes. More like space and exploration concepts. And also, the "make -believe" concept like unreal animal prints with pop colors inspiring from snakes leopards and zebra. The concept of black and silver plays the main role here along with the sportswear themes. The star dust concept banc the fashion and function that include stone wash, space graphics that completes the look.

So, by analyzing the WGSN concept of "TECH-TILITY" we can conclude the analysis by the concept of space, metallic, puffed shimmery, sequin and translucent themes. The analysis continues to the trend book called "minicool" which is exclusively for kids wear. The minicool book gives the trend, and under each trend there are 3 collection. The collection talks about the theme, colors, prints, graphics, look, silhouettes, fabrics and accessories. The concept that is been analyzed for the A/W 2020 collection for kids girls is "Ancestrally" which gives the hint of harmony, ethereal, spirituality, details and delicacy. The collection that has been chosen is "ethereal" that is so near to the WGSN forecast that has been analyzed. Ethereal talks about mysticism, universe concepts, constellations, planets, blues and purple.

- To Explore the Brands, Online Store and Analyse the Trend, Colours, Fabrics, Prints, Styles in Kids Wear.

The designing process is carried out by exploring the prevailing styles in high-end brands and online stores.In my project the exploration on prevailing styles, colors, prints, fabrics in kids wear girls offered in high-end brands like ZARA, H\&M, MANGO, ALEX \& ALEXA and TU-CLOTHING and 50+ brands was observed. [Refer Fig. 1 (A-H)]

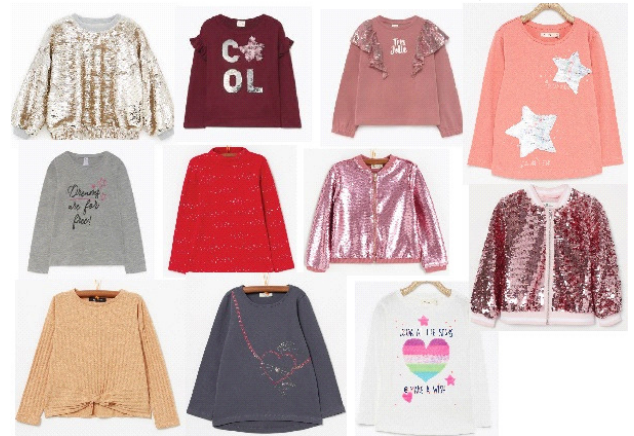

Fig. $1 \mathrm{~A}$ 


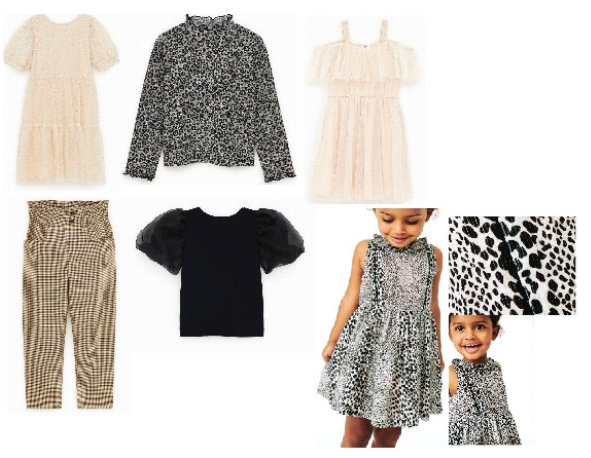

Fig. 1 B

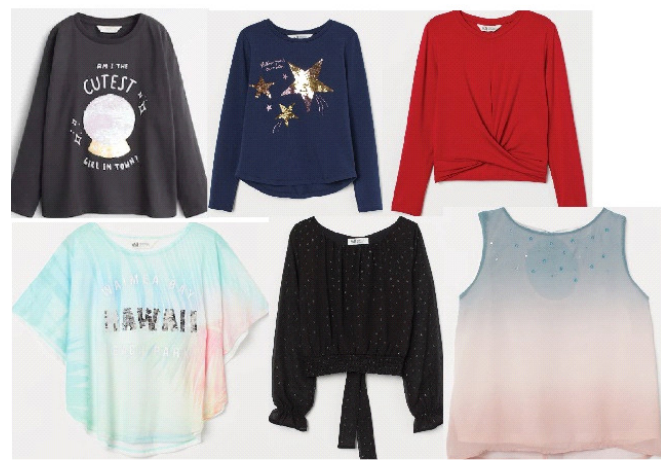

Fig. $1 \mathrm{C}$

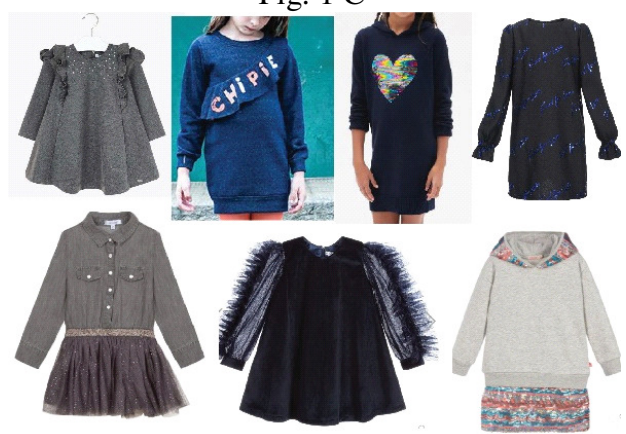

Fig. 1 D 

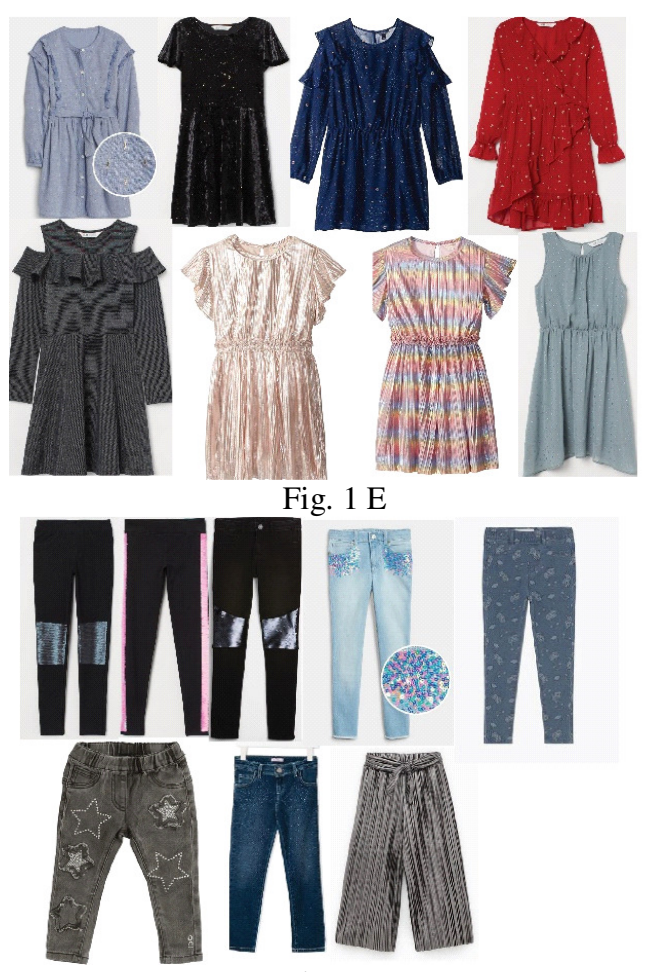

Fig. $1 \mathrm{~F}$

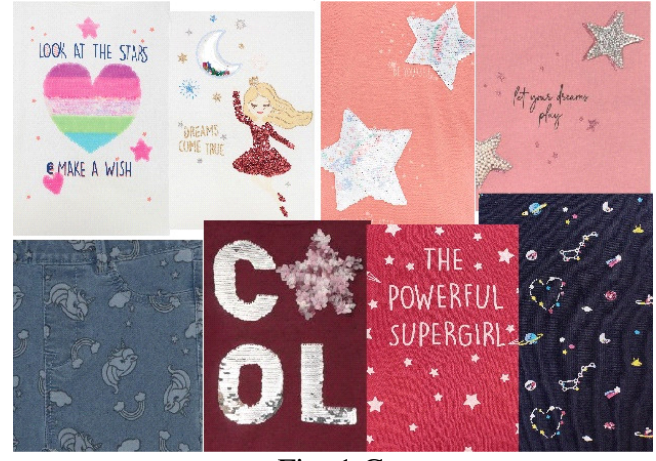

Fig. $1 \mathrm{G}$ 


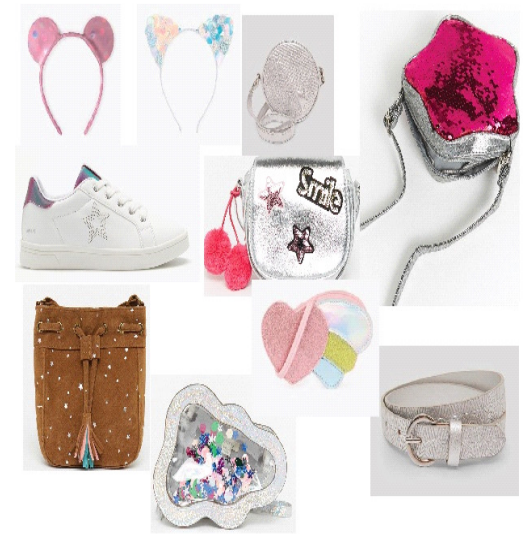

Fig. $1 \mathrm{H}$

The brand analysis are basically to understand how the concept is been implemented on the garments and also due to the marketing strategy. The fast moving styles are analyzed for the marketing purpose.

- $\quad$ To design a mood board for A/W 2020 for kid's girls(2-8yrs.)

After the exploration of the survey on brands, the next step is to create a mood board according to the concept analyzed. Mood board is the visual communication of the concept that can explain the idea of the collection. The industry practices the layout differently that anybody could understand the concept by seeing the mood board. The mood board consists of the inspiration, colors, looks, fabrics, prints \& techniques and key-looks of the concept is given in Fig. 2

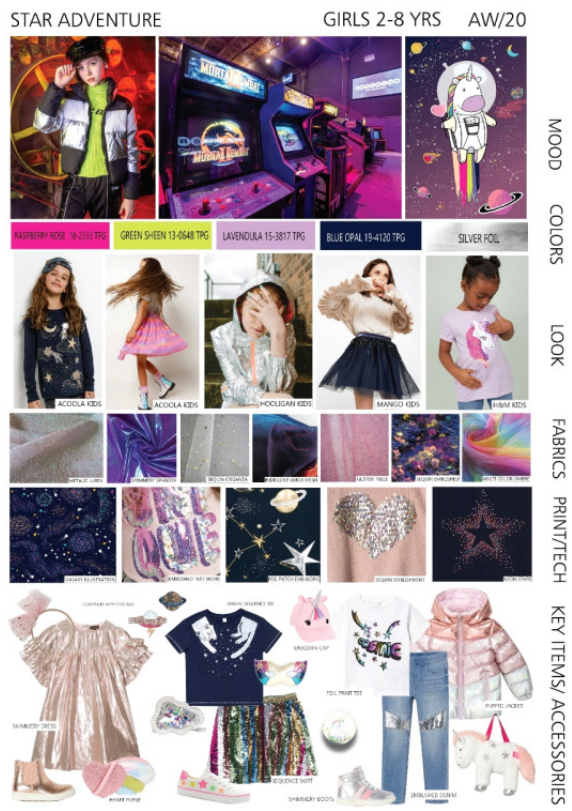

Fig. 2 
- $\quad$ Line sheet for A/W 2020 for kid's girls (2- 8 yrs.)

Line sheets are the illustration sheet that consists of a collection in different styles. The styles were designed using CAD (Adobe Illustrator CS7) and shown in Fig. 3

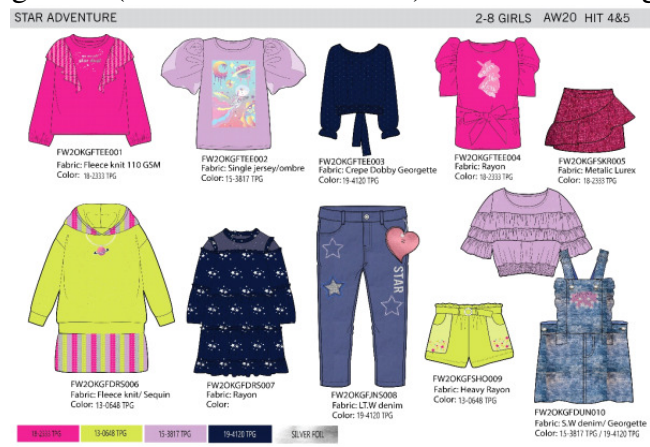

Fig. 3

The line sheets are used to do a collection that shares a specific amount of same colour or style or fabric. The style designs from the line sheet come from the same family of theme i.e., star adventure. Line sheets are also used to track the samples, from printing, dying, stitching. It is a $2 \mathrm{D}$ visualization of the garment collections for a specific season or theme.

\section{Results and discussion}

- $\quad$ Fabrics sourced for the theme

The Fabrics are sourced from China, Tirupur and some other places of India. There are varieties of knits sourced for this F/W 20 collection. Most of them are shimmery material or lurex inserted material that can relate to the space and gaming theme. Refer Fig. 4 for fabric samples.

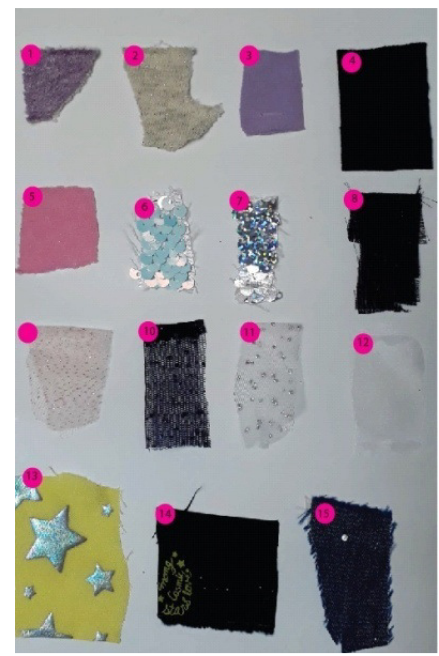

Fig. 4 
1. Loop Knit, 2. Lurex Inserted Loop Knit, 3. Single Jersey 180gsm, 4. 2x2 Lycra Rib, 5. Shimmery Knit, 6. Reversable Sequin, 7. Holographic Sequin, 8. Lurex Inserted Synthetic, 9. Glitter Knit Tulle, 10. Blue Glitter Tulle, 11. Glitter Tulle, 12. Plain Organza, 13. Holographic Printer Rayon, 14. Poplin, 15. Glitter Silk Jean.

The fabrics are sourced and matched with the collection of dresses and selected in such a way that it resonates with the style.

- $\quad$ The style and description for each design in the line sheet

The style description with the right chosen fabrics is tabled below in Table I. The Table gives the design and style details of the collection.

TABLE I Design and style details of the collection

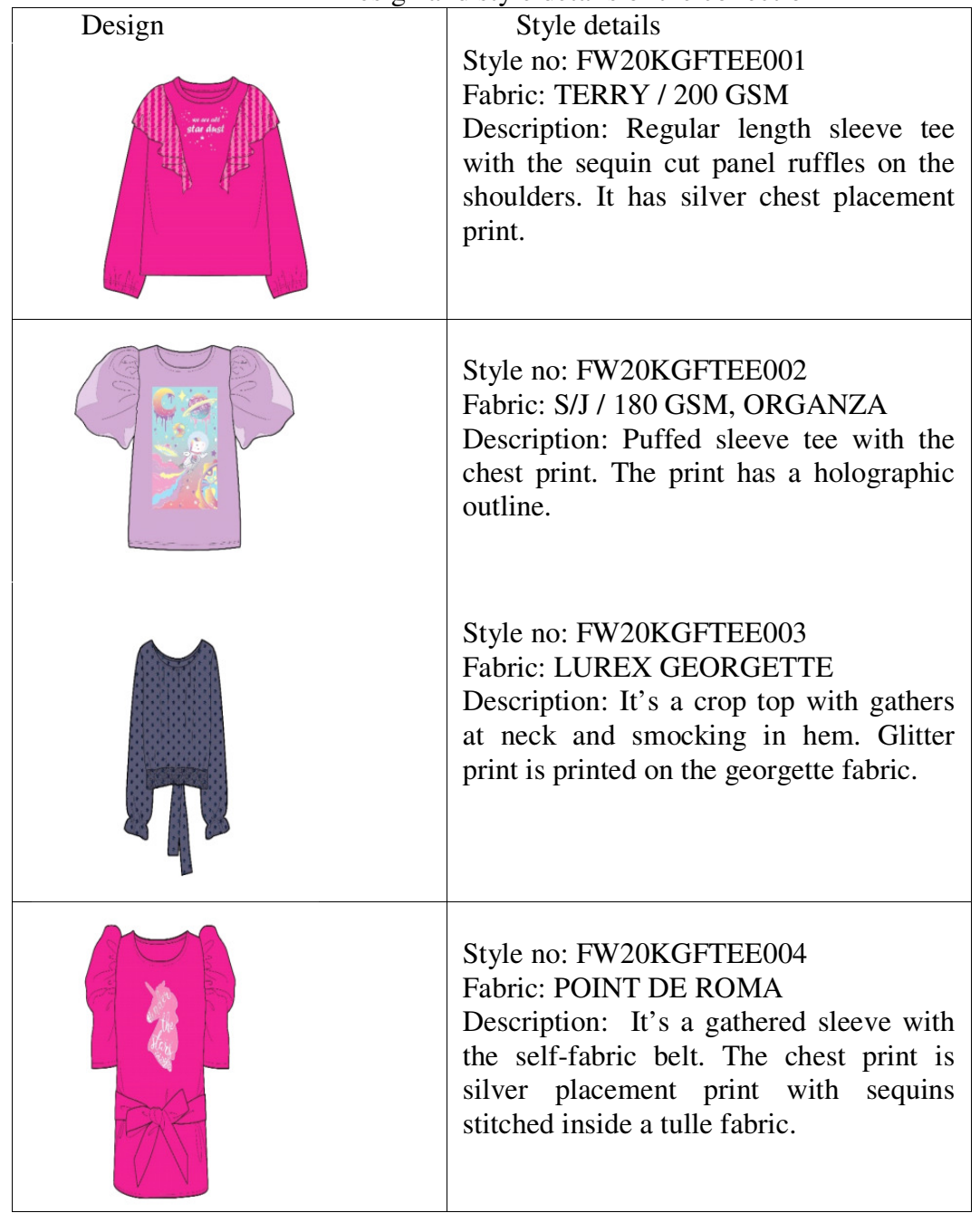




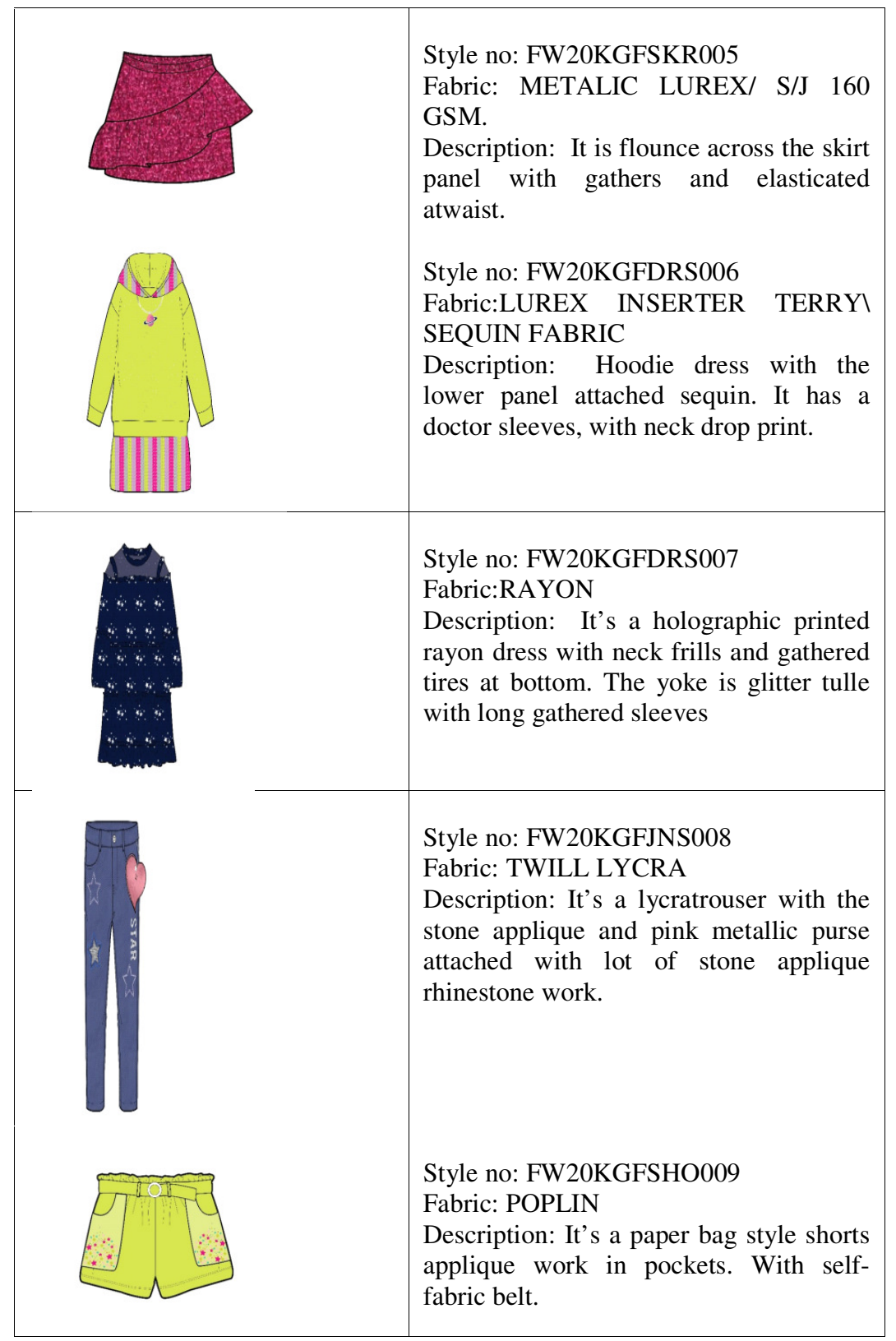




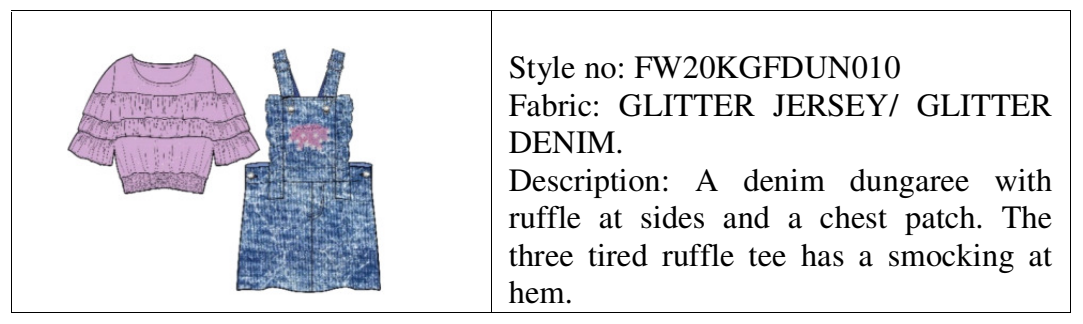

- Print artworks developed in the collection under the theme 'Star Adventure'

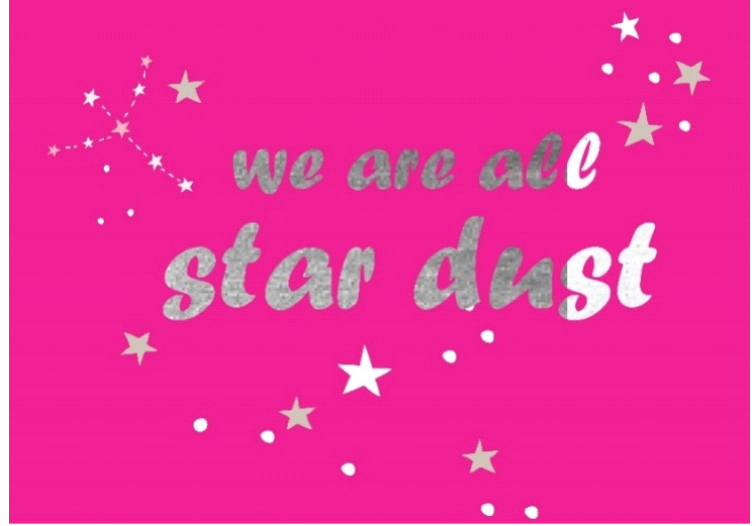

Fig. 5 Placement print

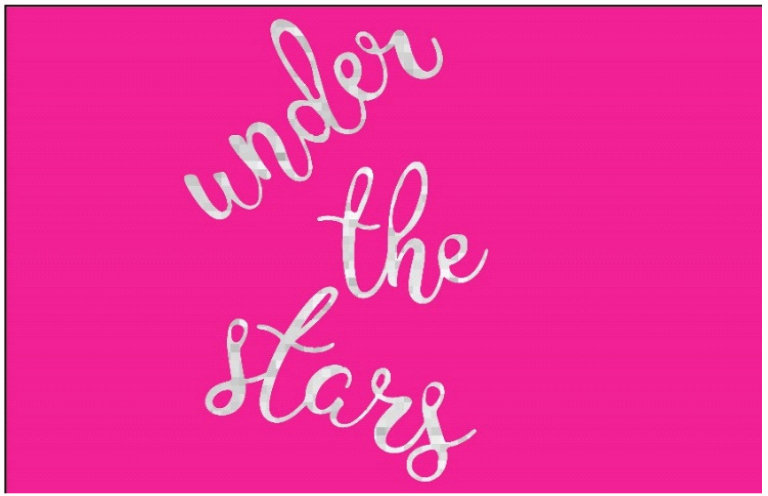

Fig. 6 Silver foil placement print 


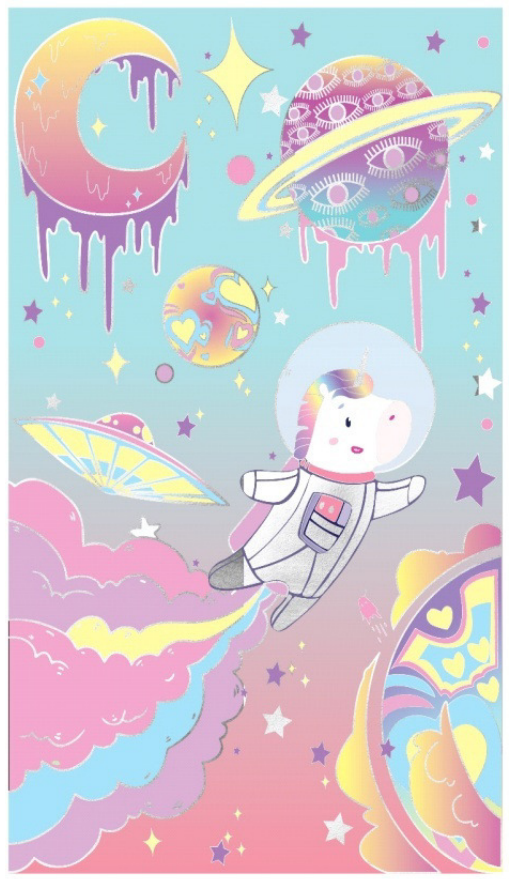

Fig. 7 Placement print

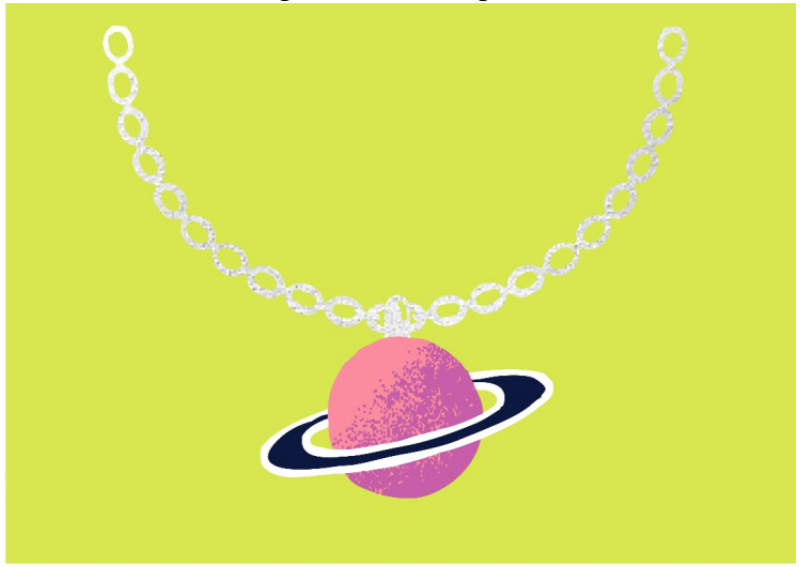

Fig.8 Neck drop print 


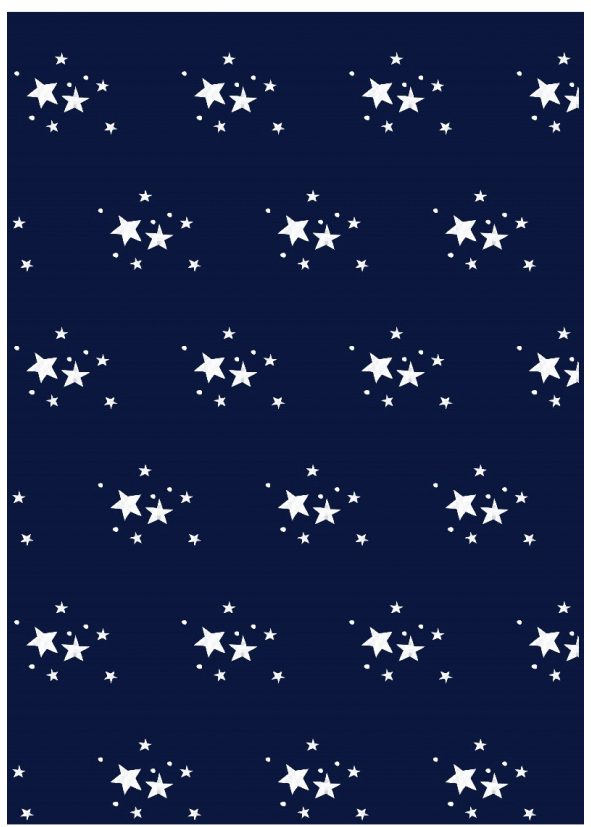

Fig.9 All over print
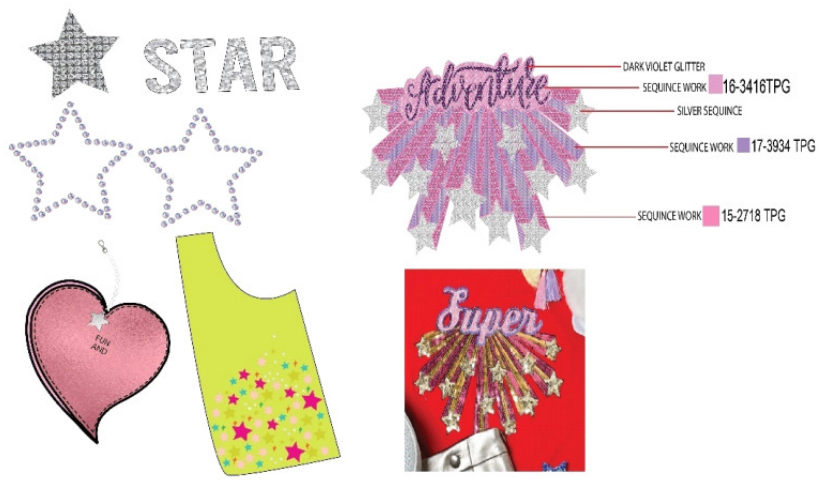

Fig. 10 Accessories and embellishments

The print art works adds aesthetic to the garment and also gives a value addition to the garment. The above figures show the print artwork in the collections. The artworks are based upon the space themes. Other than the prints there are also artworks such as rhinestone applique work and sequin patch work. The prints that are used here are Placement Print, AOPAll Over Print of foil print, Neck drop Print and Chest Print. (Fig. 5- 10)

- Tech packs for the developed collection

The techpack are technical sheets that help to understand the details in the style of the design collection. The techpack contains details about type of fabric used, type of wash, color of the fabric, type of thread, buttons, trims, description about the style details, type of print and label.

The sample of techpack is shown in the following Fig. 11 (A-C) to understand. 


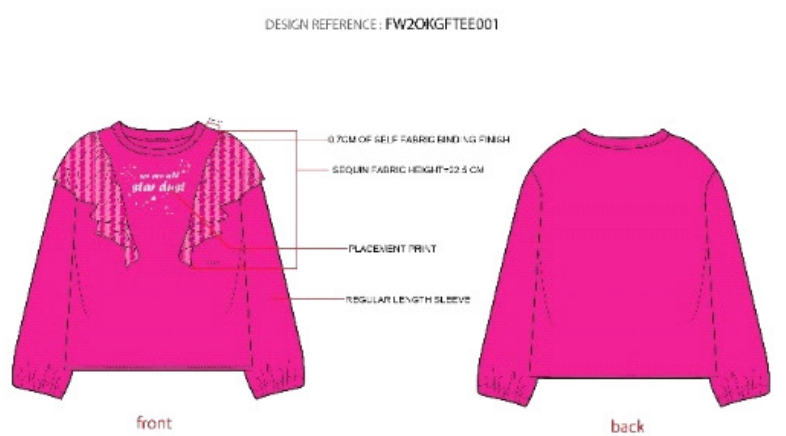

GARMENT LENGTH: 45CM

Fig. $11 \mathrm{~A}$

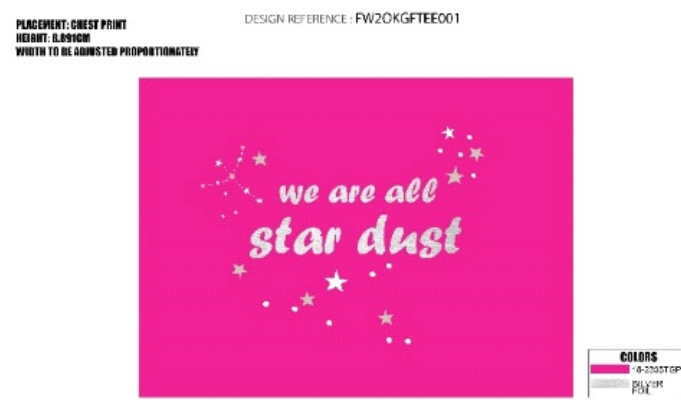

Fig. $11 \mathrm{~B}$

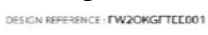

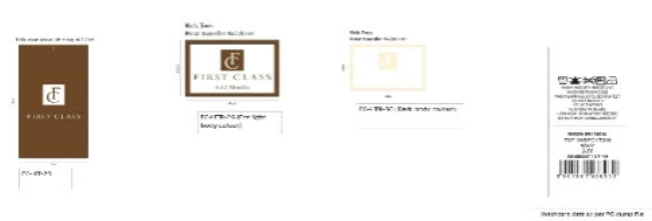

Fig. $11 \mathrm{C}$

The patterns are made using the techpack details; also the pattern master consults with the TD (Technical Designer) for the measurements of the styles. After the development of patterns for the styles, the pattern master explains the details of the styles and patterns to the cutting master. The cutting department cuts the fabric according to the pattern. Then the cut 
patterns are handed to the sewing department and the styles are stitched, buttoned, steamed and delivered.

\section{Conclusion}

Day after day, the Indian clothing market is growing rapidly in the kids clothing segment. Kid's products offer enormous potential and are growing rapidly. Being exposed to global fashion trends along with the increasing disposable income of the working class of India and existing foreign brands which acts as catalyst for the growth of the children's clothing market. The increasing brand awareness among children on the growth of the kids clothing market provides an excellent opportunity for marketers to establish a solid foundation in this segment. So, the collection was designed for 2to 8-year-old girls taking into account the above facts under the direction of the industry.

\section{Acknowledgement}

We gratefully thank M/S Reliance Trends, Bengaluru for their support in providing resources to carry out the project.

\section{References}

[1] India brand equity foundation," March 2020.

[2] B. Naqvi and S. Soni, "Indian retailing," 29 August 2019.

[3] Indian retailing," 1 March 2018.

[4] Wimalasiri, J.S. , A cross-national study on children's purchasing behavior and parental response. Journal of Consumer Marketing, 21(4): pp. 274-284, 2004.

[5] McNeal, J.U. and Ji, M.F., "Chinese children as consumers: an analysis of their new product information sources", Journal of Consumer Marketing, Vol.16, no. 4, pp. 345-364,1999.

[6] Darley, W.K. \& J.-S.Lim, Family decision making in leisure-time activities: An exploratory investigation of the impact of locus of control, child age influence factor and parental type on perceived child influence, pp. 370-374, 1986.

[7] Moschis, G. P., \& Mitchell, L. G., Television advertising and interpersonal influences on teenagers' participation in family consumer decisions. Advances in Consumer Research, 13, 181-185, 1986. 